\title{
Magnetic Bearings for Free-Piston Stirling Engines
}

P.W. Curwen

Mechanical Technology, I

Latham, New York

D.P. Fleming (Has) $B$

Lewis Research Center

Cleveland, Ohio

and

D.K. Rao and D.S. Wilson

Mechanical Technology, Inc.

Latham, New York

Prepared for the

27th Intersociety Energy Conversion Engineering Conference

cosponsored by the SAE, ACS, AIAA, ASME, IEEE, AIChE, and ANS

San Diego, California, August 3-7, 1992 


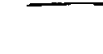

.

西

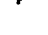

更 


\title{
MAGNETIC BEARINGS FOR FREE-PISTON STIRLING ENGINES
}

\author{
P. W. Curwen ${ }^{1}$, D. P. Fleming ${ }^{2}$, D. K. Rao ${ }^{1}$, and D. S. Wilson ${ }^{1}$ \\ ${ }^{1}$ Mechanical Technology Inc., Latham, NY \\ ${ }^{2}$ NASA Lewis Research Center, Cleveland, OH
}

27th Intersociety Energy Conversion Engineering Conference

August 3-7, 1992

San Diego, California

\section{ABSTRACT}

This paper assesses the feasibility and efficacy of applying magnetic bearings to free-piston Stirling-cycle power conversion machinery currently being developed for long-term space missions. The study was performed for a 50-kWe Reference Stirling Space Power Converter (RSSPC) which currently uses hydrostatic gas bearings to support the reciprocating displacer and power piston assemblies.

Active magnetic bearings of the attractive electromagnetic type are feasible for the RSSPC power piston. Magnetic support of the displacer assembly would require unacceptable changes to the design of the current RSSPC. However, magnetic suspension of both displacer and power piston is feasible for a relative-displacer version of the RSSPC.

Magnetic suspension of the RSSPC power piston can potentially increase overall efficiency by 0.5 to $1 \%$ ( 0.1 to 0.3 efficiency points). Magnetic bearings will also overcome several operational concerns associated with hydrostatic gas bearing systems. These advantages, however, are accompanied by a $5 \%$ increase in specific mass of the RSSPC.

\section{INTRODUCTION}

NASA and its contractors are developing freepiston Stirling engine technology for converting thermal energy into electrical energy (Stirling, 1988). Anticipated missions for this technology are long-life equipment for lunar bases, space platforms, and space exploration initiatives (SEI). Representative goals for these missions are a life of $60,000 \mathrm{hr}$, power converter specific mass less than $6 \mathrm{~kg} / \mathrm{kWe}$, and conversion efficiency greater than 25 percent (defined as net electric power out divided by thermal power delivered to the engine heater head).

As part of the Stirling Space Power Converter (SSPC) program, a Reference Stirling Space Power Converter (RSSPC) design is maintained and periodically updated. The RSSPC is a $50 \mathrm{kWe}$ space power converter which embodies the latest advances in design concepts and technology de- velopment. The power converter consists of two coaxially mounted free-piston Stirling engine/alternator modules, each of which generates $25 \mathrm{~kW}$ of electric power. Figure 1 shows the design of one of the modules.

System optimization studies have set the cold-end temperature of the RSSPC at $525 \mathrm{~K}$. Accordingly, the engine's mechanical and electrical components, including the bearings and alternator, must be designed to operate reliably at temperatures of this order. This is one of the difficult technology challenges currently being addressed, and one that must also be addressed by any alternative component technology such as magnetic bearings.

The RSSPC shown in Figure 1 is equipped with hydrostatic (pressurized) helium gas bearings to support the reciprocating power piston and displacer assemblies without sliding contact. The displacer and power pistons, in addition to their primary Stirling cycle functions, also provide pressurized helium to the bearings through a system of inlet and discharge ports, and associated internal plena. The self-contained hydrostatic bearing system has no electronic controls or moving parts (aside from the engine pistons). This results in an inherent potential for high bearing system reliability.

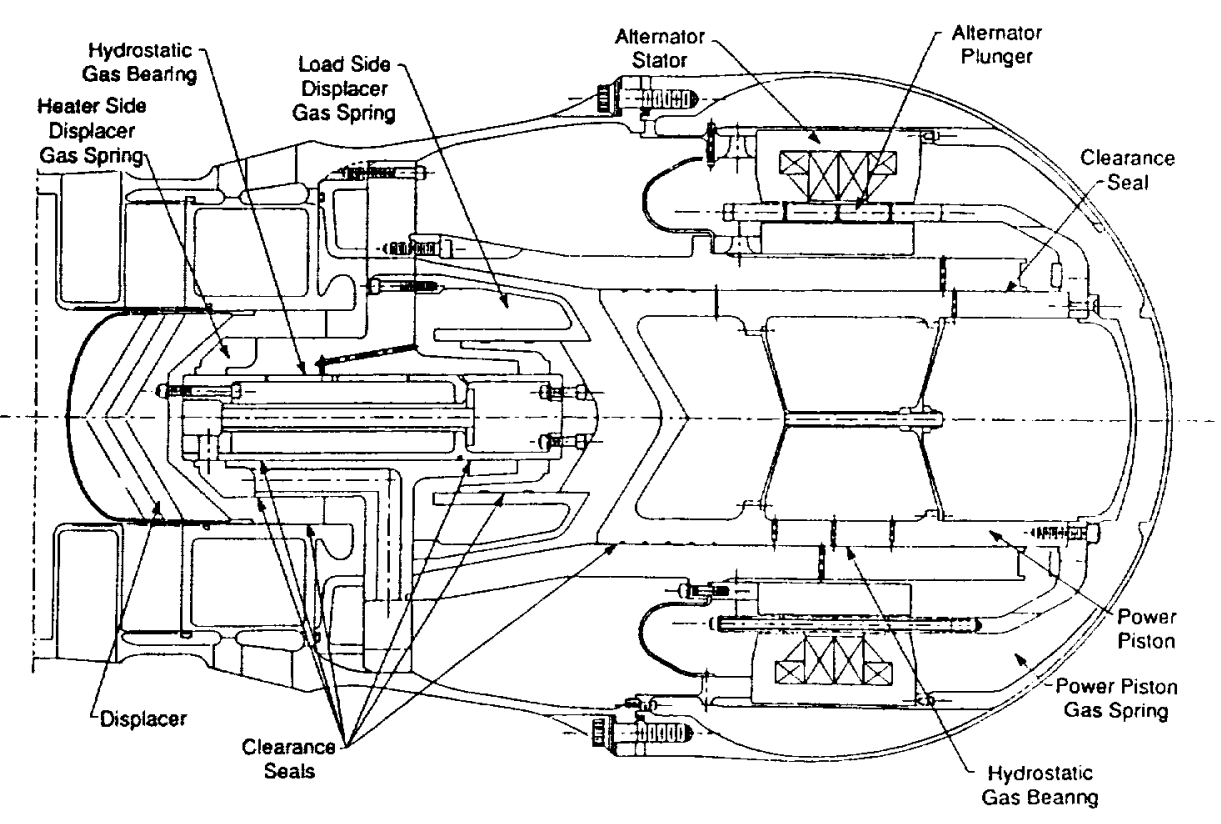

Figure 1. RSSPC Module with Hydrostatic Gas Bearings 
However, there are technical and cost issues associated with achieving this potential.

One disadvantage of this arrangement is that pressurized helium is not immediately available at engine start-up unless an auxiliary source of stored high-pressure helium is used. The RSSPC bearings are currently designed to operate with sliding contact during start-up.

Small radial clearances are required to minimize the pumping power used to pressurize the bearings. For the RSSPC, nominal radial bearing clearances range from 13 to $18 \mu \mathrm{m}(0.0005$ to 0.0007 in.). The power required to pressurize all of the hydrostatic bearings in one RSSPC module is estimated to be $485 \mathrm{~W}$. This represents $1.7 \%$ of lost output power based on $89 \%$ alternator efficiency.

Because of these disadvantages, it is desirable to evaluate other bearing types for the RSSPC. Magnetic bearings are one possible alternative. Three frequently cited attributes of magnetic bearings can be immediately recognized as advantageous to the RSSPC.

- Very low bearing system losses leading to improved overall RSSPC efficiency.

- Magnetic bearings can be electrically energized (levitated) at any time, whether or not the RSSPC is operating (assuming that electric power is available).

- Magnetic bearings can be designed with order-of-magnitude larger clearances than are required for gas bearings. This greatly reduces the problem of maintaining safe bearing clearances in the presence of differential thermal expansions, and also makes the bearings less susceptible to debris.

\section{BACKGROUND}

A literature search (Rao, 1991) was conducted as part of the feasibility study. The objectives were to update information on the state of the art of magnetic bearings for rotating and reciprocating machinery, and to make an initial assessment as to the types of magnetic bearings with the most potential for the linear free-piston RSSPC.

Magnetic force-generating mechanisms can be broadly divided into four categories: attraction force, repulsion force, shear force, and bidirectional force. Of these the most mature in terms of magnetic bearing design technology and application experience, and the one having the most potential for a high-stiffness bearing, is the attraction force mechanism. This mechanism uses opposed electromagnets as the stationary components and a ferromagnetic material, such as soft magnetic iron, as the moving component. For a given coil current, the attractive force applied by an electromagnet is inversely proportional to the square of the gap; thus the system is inherently unstable. To achieve stability, the current must be varied to one or both of the opposed electromagnets; the variation is determined by an electronic controller in response to feedback signals provided by bearing position sensors. Force bias methods are usually employed to linearize the relationship between force and control current. One popular bias method applies direct currents, called bias currents, to the magnets in addition to the control currents. Another method of bias uses opposed permanent magnets.

Magnetic bearings have heretofore been applied primarity to rotating machinery. A frequently used type is an eight-pole (foursector), all-electromagnetic, attraction-force bearing that uses dc bias and "active" dynamic control currents to achieve stability and stiffness. Conceptually, this type of bearing can also be used to support reciprocating shafts. However, because of the circumferential flux path on the journal, and the necessity that this flux path be maintained over the full reciprocating stroke, the needed amount of journal ferromagnetic material can add considerable mass to the shaft. This would certainly be the case for the RSSPC where the pistons are fabricated of beryllium specifically to minimize reciprocating mass.

Very few reciprocating applications were revealed by the literature search. The most pertinent was a split-Stirling cryocooler developed by Philips Laboratories during the 1980s (Stolfi, 1985). This cryocooler used six actively controlled, all-electromagnetic, attraction-force linear magnetic bearings to support all three of its reciprocating members. Through May 1989 , the magnetic bearings were reported to have accumulated over $60,000 \mathrm{hr}(6.8 \mathrm{yr})$ of operation without major failure.

Table 1 presents a comparison of pertinent design and performance parameters for the Philips cryocooler and the RSSPC. The RSSPC parameters represent a significant advance beyond the cryocooler requirements in almost all aspects. The most significant difference between the two applications is that the RSSPC bearings must operate in a $525 \mathrm{~K}\left(485^{\circ} \mathrm{F}\right)$ environment, whereas the cryocooler bearings operate at temperatures of about $300 \mathrm{~K}\left(80^{\circ} \mathrm{F}\right)$. Additionally, the almost fourfold increase in reciprocating frequency of the RSSPC implies that frequency response and stability characteristics of the RSSPC active bearing controllers must be carefully assessed.

\begin{tabular}{|l|l|l|l|}
\hline Parameter & $\begin{array}{l}\text { Philips } \\
\text { Cryocooler }\end{array}$ & RSSPC & $\begin{array}{l}\text { Scale } \\
\text { Factor }\end{array}$ \\
\hline Temperature, K & 300 & 525 & 1.8 \\
Stroke, mm & $5-14$ & $28-32$ & 2.3 \\
Frequency, Hz & 18 & 70 & 3.9 \\
Piston Mass, kg & $0.4-1.9$ & $3.5-20$ & 11 \\
Piston Diameter, $\mathrm{mm}$ & $25-37$ & $135-162$ & 4.4 \\
Radial Clearances, $\mu \mathrm{m}$ & 19 & $12-18$ & 0.6 \\
\hline
\end{tabular}

Table 1. Design Factors for Philips Cryocooler and RSSPC

\section{SELECTION OF BEARING TYPE FOR RSSPC}

The most commonly used attraction-force active magnetic bearing is the eight-pole (four-sector) bearing. It consists of two electromagnets per axis placed on opposite sides of the rotor. This configuration is well established, and its behavior is well documented in the literature. Following a review of various configurations, this bearing type was selected for the RSSPC based on its high stiffness capabilities plus its technical maturity and application experience. The bearing parts count could be reduced by use of a six-pole (three-sector) bearing. However, there is little experience with this configuration.

Consideration was then given to the type of bias to use -- either dc or permanent magnet bias. The potential advantage of permanent magnet bias is a reduction in bearing power consumption since a bias component of current is not required for the electromagnet coils. Some of this advantage is lost if the high-reluctance permanent magnets are located in the path of the control flux, since an increase in ampere turns of control current will then be required. This in turn requires either an increase in $i^{2} R$ coil losses or an increase in coil size (and weight). Bearing arrangements where the magnets are not in the path of the control flux are also possible (Meeks et al, 1990).

Preliminary calculations indicated that for an all-electromagnetic bearing with dc bias, maximum power consumption would he 20 to 
$56 \mathrm{~W}$ per bearing ( 3 to $12 \mathrm{~W}$ for each of four electromagnet coils plus $2 \mathrm{~W}$ per coil driver), depending on the amount of dc bias required. With four bearings (two each for displacer and power piston), total power consumption per 25-kWe RSSPC module would be 80 to $224 \mathrm{~W}$, or 0.3 to $0.9 \%$ of rated RSSPC output. Under ideal assumptions, permanent magnet bias could reduce power consumption of the coils to almost zero and total bearing control power to about $16 \mathrm{~W}$ ( $4 \mathrm{~W}$ per bearing), or about $0.06 \%$ of rated RSSPC output. The use of permanent magnet bias would thus, optimistically, increase net output power by 0.2 to $0.8 \%$ compared to bearings using $\mathrm{dc}$ bias. Weighing this minimal increase in power against the immature state of permanent magnet bias, the added mechanical complexity of incorporating permanent magnets into the bearings, and the probable increase in bearing system weight, it was decided not to pursue permanent magnet bias at this time.

\section{DESIGN OF MAGNETIC BEARINGS FOR RSSPC}

Prior to proceeding with detailed bearing design, the following general guidelines were established.

- Maximum Bearing Load Capacities. Missions for the SSPC (or any other dynamic space power conversion system) do not exist at this time. Thus there are no mission requirements that could be used to establish maximum loads for the RSSPC magnetic bearings. An arbitrary decision was made to evaluate magnetic bearing designs based on a 7-g limit load factor.

- Maximum Radial Displacements. Clearance seals for the displacer and power piston gas springs establish the maximum allowable excursions of the displacer and power piston assemblies. Since the seals should not rub, it was decided that maximum radial excursions would be limited to $25 \%$ of the design radial clearance of the seals. This allows a reasonable margin for factors such as distortions due to differential thermal expansions, long-term dc shifts in sensor calibration, and accommodation of quasi-steady-state bearing loads as might be imposed by station-keeping maneuvers.

- Changes to RSSPC Design to Incorporate Magnetic Bearings would be permissible provided they did not result in a degradation of thermodynamic performance or an increase in the size of the pressure shell.

- Location of Magnetic Bearing Electronics. Solid-state electronics operating at $525 \mathrm{~K}$ are not currently feasible. Thus low-temperature coolant fluid penetrations through the RSSPC pressure shell would be required to cool any electronics located within the shell. Alternatively, the bearing electronics could be located externally where temperatures can be more easily maintained at acceptable levels. This would result in greatly improved accessibility of the electronic modules for service or replacement. The price for this accessibility is a large number of electrical coil and sensor leads that must hermetically penetrate the pressure shell. From a system reliability standpoint, it was assumed that external location of the electronics would be preferable.

MAGNETIC BEARING CONFIGURATION - From the standpoint of integrating magnetic bearings into the RSSPC, it was apparent that minimizing radial depth of the electromagnet assemblies was more important than minimizing bearing length. Accordingly, an E-shaped lamination was selected for the electromagnets with the coil wound around the center leg. With this arrangement, only the length of the coil (rather than its diameter) would influence radial depth of the electromagnet. Ferromagnetic (soft iron) armatures for each electromagnet are attached to the moving piston and displacer assemblies. To keep moving mass of the armatures to a minimum, an axial flux path was selected (i.e., armature flux path in the same direction as piston reciprocation).

Sizing of the bearings was done using a magnetic bearing computer code. Maximum flux density was taken to be $1.8 \mathrm{~T}$; this corresponds to the use of high-saturation-flux iron-cobalt-vanadium alloys for all the magnetic materials. All of the magnet coils were assumed to have 100 turns. The zero-eccentricity air gap for all electromagnets was specified to be 0.005 in., which is 5 to 7 times the radial clearance of the various piston and displacer seals.

LOAD CAPACITY AND POWER CONSUMPTION - Calculations were made for the power piston bearing at bias currents of $1,1.5$, and $2 \mathrm{~A}$. Overall E-lamination length was 2 in. Maximum load capacity of one bearing was calculated to be $274 \mathrm{lb}$, independent of bias current. This maximum load capacity corresponds to one electromagnet operating at 1.4-T flux density (total coil current of $2.8 \mathrm{~A}$ ) and the opposing electromagnet operating at zero flux density (zero coil current). At bias currents of 1 and $2 \mathrm{~A}$, the openloop side-pull gradient of the bearing was $-27,570$ and $-110,300 \mathrm{lb} / \mathrm{in}$, respectively. To achieve a net positive bearing stiffness of 40,000 $\mathrm{lb} /$ in (the minimum deemed acceptable), open-loop proportional gains of 67,570 and $150,300 \mathrm{lb} / \mathrm{in}$. must be used.

Assuming a power piston mass of $45 \mathrm{lb}$ equally distributed between two bearings, the maximum bearing load corresponding to a load factor of $7 \mathrm{~g}$ is $158 \mathrm{lb}$ per bearing. To prevent contact of the piston gas spring seal, the bearing stiffness must be about 275,000 Ib/in., requiring an open-loop proportional gain of about 385,000 $\mathrm{lb} / \mathrm{in}$ for a bias current of $2 \mathrm{~A}$. Gains of this magnitude may result in unstable bearings; the bearings would probably require increased pole area, and hence size, to meet a $7 . \mathrm{g}$ stiffness requirement.

The amount of $\mathrm{dc}$ bias required will depend on the magnitude of the small-amplitude stiffness required; higher stiffnesses require higher bias currents and higher proportional gains. If dynamic analysis shows that a bearing stiffness of $40,000 \mathrm{lb} / \mathrm{in}$. is acceptable, then a $1 \mathrm{~A}$ bias current can be used. De power consumption per bearing due to the bias current varies from $12 \mathrm{~W}$ at $1 \mathrm{~A}$ to $48 \mathrm{~W}$ at $2 \mathrm{~A}$ (coil losses only). While these losses may seem high compared to other magnetic bearing applications, it must be remembered that at the coil operating temperature of $550 \mathrm{~K}\left(530^{\circ} \mathrm{F}\right)$ the resistivity of copper is twice its room temperature value.

Total power consumption in the coils will depend on the magnitude of the bearing control current as determined from bearing system dynamic analysis. Assuming a bearing displacement amplitude of $0.5 \mathrm{mil}$, the analysis predicts a maximum dynamic control current amplitude of $0.29 \mathrm{~A}$. Power loss due to this control current would be $0.5 \mathrm{~W}$ per bearing which can be neglected compared to the bias power loss.

The inductance and room temperature coil resistance of each electromagnet will be about $0.039 \mathrm{H}$ and $1.5 \mathrm{Q}$, respectively. These values yield an intrinsic room temperature time constant for each electromagnet of $0.026 \mathrm{sec}$. At the RSSPC operating temperature, coil resistance will increase to about 3.0 \& with a corresponding reduction in time constant to $0.013 \mathrm{sec}$.

\section{FITTING MAGNETIC BEARINGS TO RSSPC}

MECHANICAL DESIGN - Figure 2 shows a cross-section of the magnetic bearing assembly for the RSSPC power piston. The eight bearing electromagnets are shown mounted inside the bore of the piston via an arbor that is bolted to the end of the power piston 
cylinder. This mounting arrangement requires the attachment points between the power piston and alternator plunger to straddle the arbor-to-cylinder mounting tabs and, consequently, requires that rotation of the piston be prevented. It has been demonstrated in the SSPC program that a strong anti-rotation torque is provided by the magnetic circuit design of the alternator. When energized, the magnetic bearings will also provide anti-rotation torque.

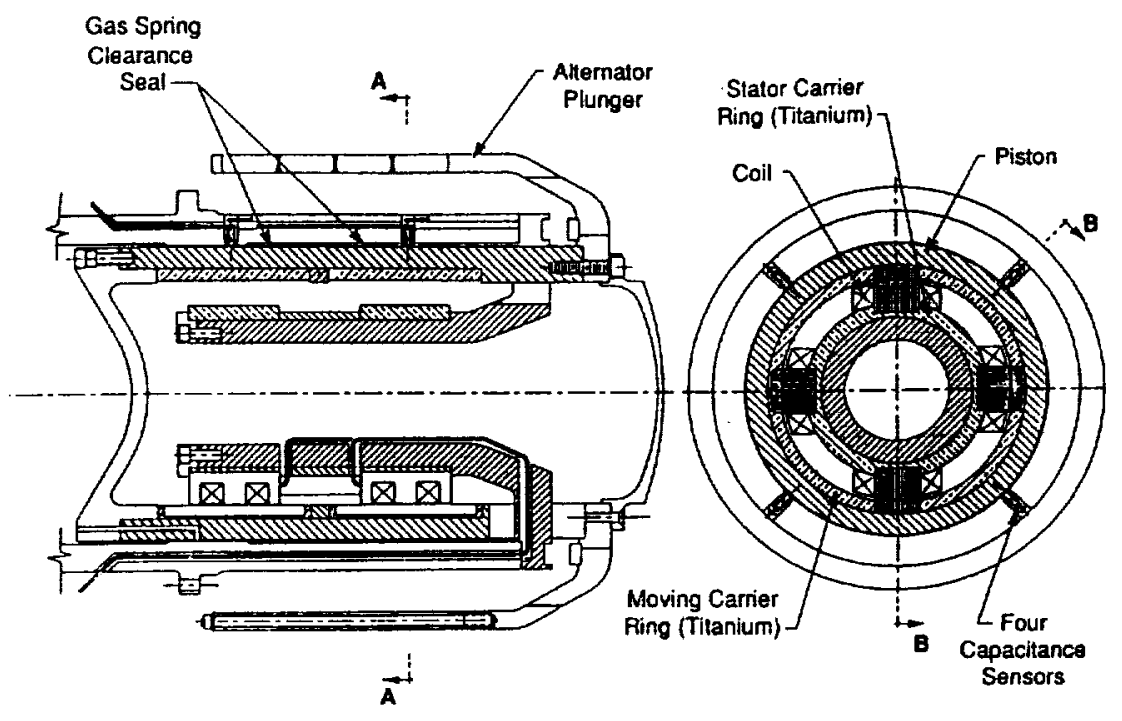

Figure 2. Magnetic Bearing Assembly for RSSPC Power Piston.

of $48 \mathrm{~W}$, the maximum coil temperature will be about $310^{\circ} \mathrm{C}$ (Curwen et al, 1991). While this is less than the $325^{\circ} \mathrm{C}$ maximum temperature predicted for the alternator coils, it falls in the same category in the sense that a proven wire insulation that will last for $60,000 \mathrm{hr}$ has not yet been identified. Mechanical design of the electromagnet coils, particularly the means for holding them in position while maintaining good thermal coupling between the coils and the E-lamination stacks, will probably be the most difficult aspect of magnetic bearing design for the RSSPC. This is solely the result of the temperature levels involved. In this regard, current development work being performed by Pratt \& Whitney Aircraft for the U.S. Air Force is highly pertinent since this work is directed at magnetic bearing temperatures of $400^{\circ} \mathrm{C}$ (Hibner \& Bansal, 1991).

EFFECT ON RSSPC MASS - Calculated weight of the stationary iron and coils for one bearing is 1.1 $\mathrm{kg}(2.5 \mathrm{lb})$. For a piston stroke of 1.4 in., the weight of moving iron for one bearing is $0.8 \mathrm{~kg}(1.8 \mathrm{lb})$. Total electromagnetic weight for one power piston magnetic bearing is then $1.9 \mathrm{~kg}(4.3 \mathrm{lb})$.

Including mounting hardware, estimates of magnetic bearing system mass and specific mass for one 25-kWe RSSPC engine module (i.e., two bearings supporting one power piston) are $7.0 \mathrm{~kg}$ and 0.28 $\mathrm{kg} / \mathrm{kWe}$, respectively. Because there is very little mass directly attributable to the gas bearings, incorporation of magnetic bearings into the RSSPC will increase total mass over that of the gas bearing RSSPC by

Both the moving iron armatures and the stationary E-lamination stacks for each of the eight electromagnets are fabricated as packets of magnetic laminations welded into carrier rings made of titanium. The carrier rings, together with bearing spacer rings, are then shrunk into the ID of the beryllium piston and onto the $O D$ of the stationary mounting arbor. The shrink-fitted parts are axially locked into position by bolted flanges. Since beryllium has a higher coefficient of thermal expansion than titanium, the shrink-fit interference at room temperature is of the order of $0.010 \mathrm{in}$. Careful design of the resulting composite structures, particularly the piston structure, is required to minimize thermal distortion at RSSPC operating temperature and to ensure long-term dimensional stability.

After considerable effort to incorporate magnetic bearings into the displacer assembly, it was concluded this could be done only by increasing the diameter of the RSSPC cooler and regenerator to allow OD mounting of the bearing electromagnets. This would also require increasing the RSSPC pressure shell diameter. The result of these modifications would be reduced RSSPC efficiency and increased weight, which were unacceptable under the study guidelines. Internally mounting the electromagnets at the dome end of the displacer was likewise infeasible because of the numerous passages and ports associated with operation of the gas springs.

During the conduct of this study, an alternative RSSPC concept was introduced, the "relative-displacer" RSSPC. In it, the displacer is sprung via gas springs from the power piston, rather than from the engine frame. Although not discussed herein, magnetic bearings were found to be feasible for the displacer as well as the power piston of the relative-displacer RSSPC (Curwen et al, 1991).

HEAT TRANSFER - Losses for the power piston bearings will range from 12 to $48 \mathrm{~W}$ per bearing, depending on the amount of bias current required. Based on conservative calculations for a loss essentially the amount of the magnetic bearing system mass. The specific mass goal for the RSSPC is $6 \mathrm{~kg} / \mathrm{kWe}$. Thus the increase in RSSPC specific mass due to incorporation of power piston magnetic bearings represents $5 \%$ of this goal. These mass estimates do not include the mass of the magnetic bearing electronics.

RSSPC EFFICIENCY - The overall efficiency predicted for the RSSPC with hydrostatic gas bearings is $27.4 \%$. Losses due to the power piston bearings are estimated to be $315 \mathrm{~W}$ per RSSPC module; this represents $280 \mathrm{~W}$ of lost electric output at an alternator efficiency of 89 percent. The magnetic bearing system losses including control electronics range from 43 to $146 \mathrm{~W}$; the predominant factor influencing this range is the amount of bias current. Thus net power output per module will increase by 135 to $238 \mathrm{~W}$ with magnetic bearings; the corresponding improvement in overall RSSPC efficiency will be 0.5 to $1 \%$ (0.1 to 0.3 efficiency points).

\section{DYNAMICS OF RSSPC ENGINE-BEARING SYSTEM}

An important aspect of applying magnetic bearings to the RSSPC is ensuring that the dynamics of the resulting engine-bearing system are acceptable. System dynamics as discussed here pertain to both intrinsic system stability and response of the magnetically supported power piston to internally and externally imposed excitation.

Extensive dynamics studies were performed for the SSPC (Stirling, 1988). These studies revealed that angular misalignments of the SSPC displacer and power piston relative to their various clearance seals can produce significant dynamic radial gas forces at reciprocating frequency. Under conditions of low bearing stiffness, it was shown that the piston-bearing system can be unstable as a consequence of these seal forces. Since magnetic bearings have significantly lower stiffness than gas bearings, and also require 
closed-loop feedback techniques to overcome their inherent instability characteristics, the question of overall RSSPC system stability received high priority in this study.

UNDAMPED OPEN-LOOP NATURAL FREQUENCIES Using data for the masses and inertias of the power piston together with the corresponding center of gravity and bearing locations, the two undamped rigid body natural frequencies were computed for the coupled translational and angular displacement modes of the power piston. These natural frequencies are plotted as functions of bearing stiffness in Figure 3. Constant bearing stiffness and open-toop system configuration (i.e., no feedback loops) were assumed.

In a transverse $1-\mathrm{g}$ gravitational field, the reciprocating motion of the pistons will give rise to an exciting moment at the second harmonic of reciprocating frequency. Accordingly, it is desirable that both rigid-body natural frequencies be well removed from, and preferably above, both the fundamental and second harmonic of the RSSPC operating frequency.

Figure 3 illustrates that the first natural frequency is very close to the $70-\mathrm{Hz}$ RSSPC operating frequency for a bearing stiffness of $40,000 \mathrm{lb} / \mathrm{in}$. Furthermore, for this stiffness the second natural frequency is very close to the second harmonic of operating frequency. This implies that significant damping may be required to minimize vibration amplitudes. Potential sources of damping are gas film damping from the piston gas spring clearance seal and electromagnetic damping from the magnetic bearings. However, it would be desirable to have higher bearing stiffness, say $80,000 \mathrm{lb} / \mathrm{in}$., so that the first natural frequency would be substantially above the RSSPC operating frequency. In a qualitative sense, the more that open-loop natural frequencies can be increased above RSSPC operating frequency, the greater will be the likelihood of stable closed-loop operation. Of course, the true dynamic response will be determined by the closed-loop dynamics of the magnetic bearing-piston system.

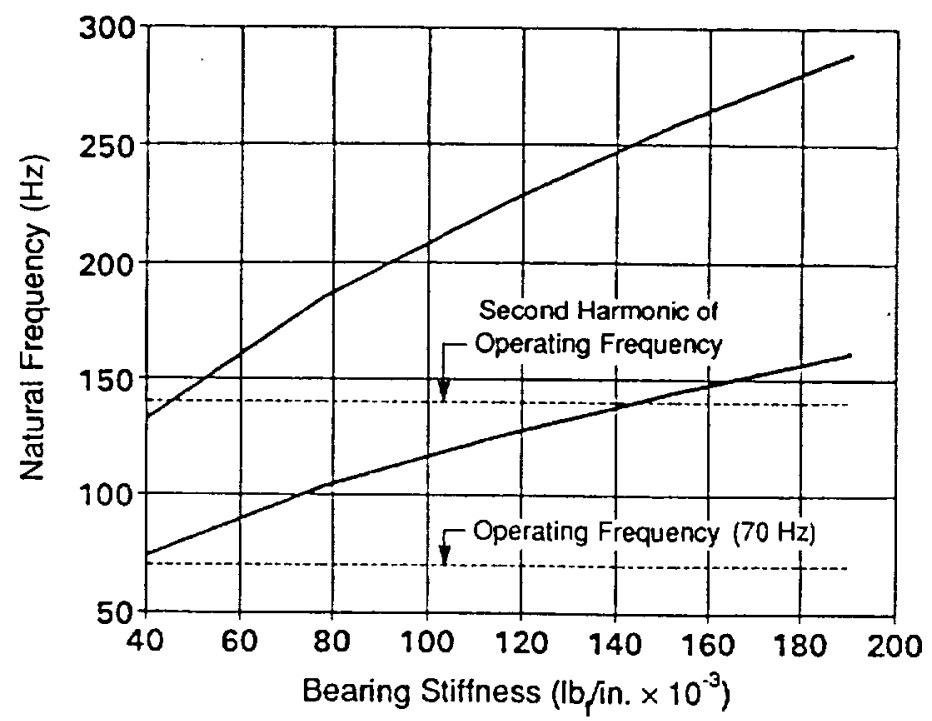

Figure 3. Power Piston Open-Loop Natural Frequencies.

The hydrostatic gas bearings used in the RSSPC have predicted stiffnesses greater than $600,000 \mathrm{lb} / \mathrm{in}$. At these high stiffnesses, the 70-Hz RSSPC operating frequency falls well below all of the power piston natural frequencies. In addition, the hydrostatic bearings provide a large amount of damping. Accordingly, stable operation of the RSSPC has been predicted. Testing under the SSPC contract has so far confirmed these predictions.

RSSPC DYNAMIC RESPONSE - Under the SSPC program, existing hydrostatic bearing and scal analysis computer codes were combined into a PC-based, time-stepping, graphics-output code to evaluate transient response and stability of the RSSPC under the influence of alternator, bearing, seal, and porting forces. This code accounts for both axial and circumferential flow components in the hydrostatic bearings and clearance seals, and allows for both transverse and angular rigid-body degrees of freedom. The code allows mid-stroke ports or grooves to be incorporated into seal regions, and accounts for time-varying boundary pressures at the ends of bearings and seals, as well as time-varying supply and exhaust pressures for ports.

Under the current effort, this code was extended to allow modeling of magnetic bearings, including closed-loop proportional, integral, and derivative (PID) control of the bearings based on bearing position feedback. The magnetic bearing model includes the magnetic side-pull gradient of the bearings due to the bias current, plus a second-order differential equation representation of coil driver circuits (i.e., power amplifiers) using control current feedback. (In common with other magnetic bearing systems, without current feedback the bearings would always be unstable because of the high inductance (long time constant) of the bearing coils.) Based on frequency response characterizations of coil driver circuits, achievable values for the dynamics parameters of the coil driver transfer function were: time constant, $0.10 \mathrm{msec}$ (corresponding to a characteristic frequency of $1590 \mathrm{~Hz}$ ), and damping ratio, 0.5 .

All dynamics calculations for the power piston were made using the following constant design and control parameters for each of the two magnetic bearings used to support the piston:

- Current stiffness: $\quad 275.7 \mathrm{lb} / \mathrm{A}$

- Magnetic side-pull gradient: $-110,300 \mathrm{lb} / \mathrm{in}$

- Open-loop integral gain: $1.35 \times 10^{6} \mathrm{lb} / \mathrm{in}-\mathrm{sec}$

Nominal (initial) control settings for the bearings are listed below. These settings were varied (the same for both bearings) to achieve system stability.

- Open-loop proportional gain at $70 \mathrm{~Hz}: 150,300 \mathrm{lb} / \mathrm{in}$

- Open-loop derivative gain at $70 \mathrm{~Hz}: \quad 100 \mathrm{lb}-\mathrm{sec} / \mathrm{in}$

The effective stiffness of each bearing at $70 \mathrm{~Hz}$ (i.e., at RSSPC operating frequency) is the sum of the open-loop proportional gain and the magnetic side-pull gradient, or $40,000 \mathrm{lb} / \mathrm{in}$. for the initial proportional setting.

The design-point radial clearance of the piston gas spring seal was 0.0007 in. Calculations were made for significant variations around this nominal clearance.

Alternator side-pull (from as-built eccentricities) was taken to be $50 \mathrm{lb}$ with an alternator side-pull gradient of $-10,600 \mathrm{lb} / \mathrm{in}$. Both 0-g and 1-g conditions were evaluated with respect to total bearing loading.

The nominal bearing and coil driver parameters yield stable solutions in the absence of any seals. In the absence of excitation forces (no loading from seals, ports, alternator, or gravity), a simple, slightly underdamped transient response was obtained without any steady-state oscillations. Figure 4 shows that the introduction of a constant $50-\mathrm{lb}$ alternator side-pull force produces a steady-state $70-\mathrm{Hz}$ response amplitude of 0.03 mil at the piston center of gravity. The addition of a 1-g transverse gravitation field significantly increased the steady-state center-of-gravity response amplitude to 0.18 mil. However, there was no evidence of any second-harmonic component in this response.

The system became unstable when the characteristic time of the coil driver circuits was increased from 0.1 to $0.45 \mathrm{msec}$. This instability persisted over the investigated range of controller derivative gain from 25 to $300 \mathrm{lb}$-sec/in. The instability frequency 
was about $210 \mathrm{~Hz}$, well above the open-loop undamped rigid-body natural frequencies of the piston for a bearing stiffness of 40,000 lb/in. This implies that the closed-loop magnetic bearing system effectively raises the system natural frequencies, but the closed-loop effective damping becomes negative at a characteristic time of 0.45 msec.

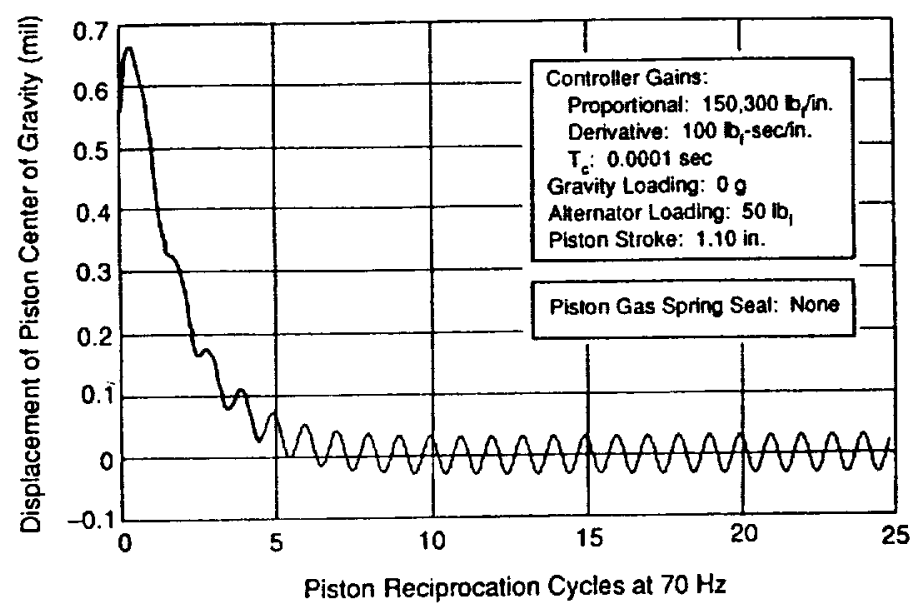

Figure 4. Power Piston Response: Alternator Loading Only.

In other cases, proportional and derivative gains were increased and the piston gas spring seal was included with radial clearances from 0.3 to 1.5 mil. All of these cases produced stable responses for a characteristic time of $0.1 \mathrm{msec}$ for the coil driver circuits. As would be expected, increases in proportional gain resulted in smaller steady-state response amplitudes. Figure 5, for the nominal gain settings and all anticipated forcing functions active, shows that the response transient decays rapidly at the 0.7 -mil design clearance of the gas spring seal. The final steady-state response of Figure 5 clearly shows a small second-harmonic component of RSSPC operating frequency due to the $1-\mathrm{g}$ gravitational field assumed for this calculation.

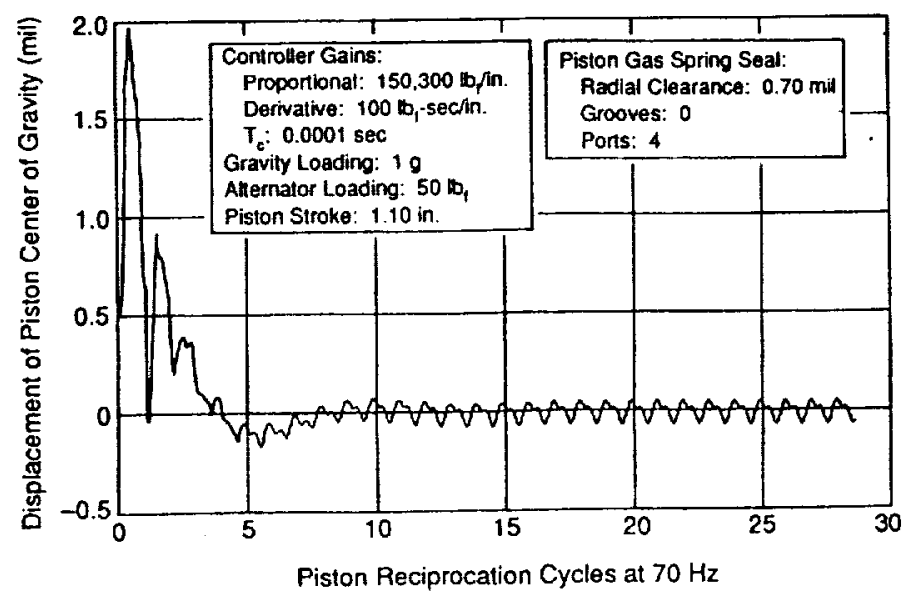

Figure 5. Power Piston Response: Alternator, Gravity, Seal, and Port Loads.

Based on this investigation, stable operation of the RSSPC on magnetic bearings is feasible; However, stability cannot be taken for granted. Considerably more investigation is needed to fully under- stand the stability characteristics of this type of machinery. It is clearly a complex dynamics situation with a number of possible significant parameters.

\section{CONCLUDING REMARKS}

Magnetic bearings appear to offer a technically feasible alternative for the RSSPC power piston assembly and, in the case of the relative-displacer RSSPC, for the displacer assembly as well. Magnetic bearings overcome the major concerns of hydrostatic gas bearings, namely start/stop sliding and orifice plugging. However, they also increase system complexity and require more penetrations of the engine pressure shell.

Use of magnetic bearings on the RSSPC power piston will improve overall efficiency by 0.5 to $1 \%$ ( 0.1 to 0.3 efficiency points), depending on the amount of bias current required for the magnetic bearings. At the same time, magnetic bearings will increase total mass of the RSSPC by approximately $14 \mathrm{~kg}$. This increase represents $5 \%$ of the $6 \mathrm{~kg} / \mathrm{kWe}$ specific mass goal for the RSSPC.

The preferred type of magnetic bearing is the attraction-force active magnetic bearing. Selection of this bearing type is based on its high stiffness capabilities plus its technical maturity and application experience. The feasibility results reported herein are based on four-sector bearing designs using dc bias. With regard to overall RSSPC efficiency improvement, there does not appear to be a significant impetus to use permanent magnet bias, rather than $\mathrm{dc}$ bias.

\section{ACKNOWLEDGEMENTS}

This work was supported by NASA Contract NAS3-26061. The authors would like to acknowledge valuable technical contributions by Dr. H. Ming Chen, Dr. M. Dhar, Mr. J. Kralick, and Dr. J. A. Walowit.

\section{REFERENCES}

Curwen, P. W., Rao, D. K, and Wilson, D. S., 1991: A Feasibility Assessment of Magnetic Bearings For Free-Piston Stirling Power Converters. NASA CR-189135.

Hibner, D. H., and Bansal, P. N., 1991: Magnetic Bearing Feasibility and Development. USAF WL-TR-91-2040.

Meeks, C. R., Schwartz, S. D., Spencer, V., and Kascak, A., 1990: Design of a Highly Efficient Magnetic Bearing for Cryogenic Applications. NASA Conference on Advanced Earth-10-Orbit Propulsion Technology.

Rao, D. K, 1991: Assessment of Magnetic Bearing Concepts for Stirling Space Engines. Mechanical Technology Inc. 90TR46.

Stirling Space Engine Program, 1988. NASA Contract NAS3-25463.

Stolfi, F., and deJonge, A. K., 1985: Stirling Cryogenerators with Linear Drive. Philips Technical Review, Vol. 42, No. 1, pp. 1-10. 

Public reporting burden for this collection of information is estimated to average 1 hour per response, including the time for reviewing instructions, searching existing data sources, gathering and maintaining the data needed, and completing and reviewing the collection of information. Send comments regarding this burden estimale or any other aspect of this collection of information, including suggestions tor reducing Davis Highway, Suite 1204, Artington, VA $22202-4302$, and to the Otice of Managentent and Budd

1. AGENCY USE ONLY (Leave blank) 2. REPORT DATE August 1992 3. REPORT TYPE AND DATES COVERED

\section{TITLE AND SUBTITLE}

Magnetic Bearings for Free-Piston Stirling Engines

6. AUTHOR(S)

WU-590-13-11

P.W. Curwen, D.P. Fleming, D.K. Rao, and D.S. Wilson

7. PERFORMING ORGAMIZATION NAME(S) AND ADDRESS(ES)

8. PERFORMING ORGANIZATION REPORT NUMBER

National Aeronautics and Space Administration

Lewis Research Center

E-7091

Cleveland, Ohio 44135-3191

9. SPONSORING/MONITORING AGENCY NAMES(S) AND ADDRESS(ES)

10. SPONSORING/MONITORING

National Aeronautics and Space Administration

Washington, D.C. 20546-0001 AGENCY REPORT NUMBER

NASA TM-105730

\section{SUPPLEMENTARY NOTES}

Prepared for the 27th Intersociety Energy Conversion Engineering Conference, cosponsored by SAE, ACS, AIAA, ASME, IEEE, AIChE, and ANS, San Diego, California, August 3-7, 1992. P.W. Curwen, Mechanical Technology, Inc., 968 Albany-Shaker Road, Latham, New York 12110; D.P. Fleming, NASA Lewis Research Center, Cleveland, Ohio; and D.K. Rao and D.S. Wilson, Mechanical Technology, Inc., 968 Albany-Shaker Road, Latham, New York 12110. Responsible person, D.P. Fleming , (216) 433-6013.

12a. DISTRIBUTION/AVAILABILITY STATEMENT

12b. DISTRIBUTION CODE

Unclassified - Unlimited

Subject Category 37

\section{ABSTRACT (Maximum 200 mords)}

This paper assesses the feasibility and efficacy of applying magnetic bearings to free-piston Stirling-cycle power conversion machinery currently being developed for long-term space missions. The study was performed for a 50-kWe Reference Stirling Space Power Converter (RSSPC) which currently uses hydrostatic gas bearings to support the reciprocating displacer and power piston assemblies. Active magnetic bearings of the attractive electromagnetic type are feasible for the RSSPC power piston. Magnetic support of the displacer assembly would require unacceptable changes to the design of the current RSSPC. However, magnetic suspension of both displacer and power piston is feasible for a relative-displacer version of the RSSPC. Magnetic suspension of the RSSPC power piston can potentially increase overall efficiency by 0.5 to $1 \%$ ( 0.1 to 0.3 efficiency points). Magnetic bearings will also overcome several operational concerns associated with hydrostatic gas bearing systems. These advantages, however, are accompanied by a $5 \%$ increase in specific mass of the RSSPC.

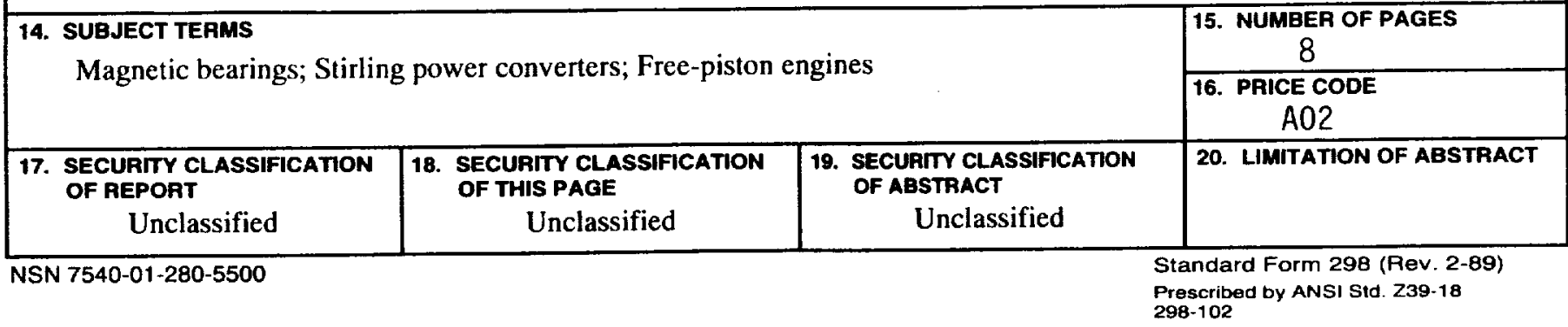

